\title{
Correction to: Challenges and future directions in breast cancer care in Fukushima prefecture in Japan: correspondence to "A survey on the current status of clinical resources for diagnosis and treatment of breast cancer in rural hospitals of the Tohoku region in Japan"
}

\author{
Akihiko Ozaki ${ }^{1}\left[\right.$ Kazunoshin Tachibana ${ }^{2} \cdot$ Tohru Ohtake $^{2}$ \\ Published online: 13 October 2021 \\ (c) The Author(s), under exclusive licence to The Japanese Breast Cancer Society 2021
}

\section{Correction to: Breast Cancer (2021) 28:1163-1164 \\ https://doi.org/10.1007/s12282-021-01254-9}

In the original publication of the article, the first sentence in the first paragraph should start as "Ishida et al. investigated the current status ..." and not "Ishikawa et al. ...".

Publisher's Note Springer Nature remains neutral with regard to jurisdictional claims in published maps and institutional affiliations.

The original article can be found online at https://doi.org/10.1007/ s12282-021-01254-9.

Akihiko Ozaki

ozakiakihiko@gmail.com

1 Department of Breast Surgery, Jyoban Hospital of Tokiwa Foundation, 57 Kaminodai, Jyoban-Kamiyunaga-Yamachi, Iwaki, Fukushima 972-8322, Japan

2 Department of Breast Surgery, Fukushima Medical University School of Medicine, Fukushima, Fukushima, Japan 